\title{
La formación de talento e innovación a través de la vinculación y los modelos de hélice basados en la sociedad del conocimiento
}

\author{
The Formation of Talent and Innovation Through Linking and Helix Models \\ Based on the Knowledge Society
}

\begin{abstract}
Treinamento e inovação de talentos por meio de modelos de ligação e hélice baseados na sociedade do conhecimento
\end{abstract}

Evelio Gerónimo Bautista

Universidad del Valle de Atemajac, México evelio.geronimo@univa.mx https://orcid.org/0000-0001-6795-0404

Rocío Calderón García

Universidad de Guadalajara, México rocio.calderon@redudg.udg.mx https://orcid.org/0000-0003-0716-3446

\section{Resumen}

El objetivo primordial de este artículo es explicar de qué forma incide la formación de talento y la innovación en los procesos de vinculación que se llevan a cabo entre las universidades y la sociedad civil y organismos empresariales. Lo anterior mediante un estudio de caso sobre la industria mueblera de Jalisco, a través del modelo de triple hélice, cuádruple hélice y quíntuple hélice. Uno de los resultados contundentes es que la formación de talento y la innovación influyen en el fortalecimiento del sector mueblero jalisciense. Asimismo, en el campo de la vinculación se percibe la conformación de actores clave a nivel local y nacional para la integración de una red de agentes heterogéneos esenciales para la generación de desarrollo y crecimiento de este sector. Ahí, las instituciones de educación enfrentan el gran 


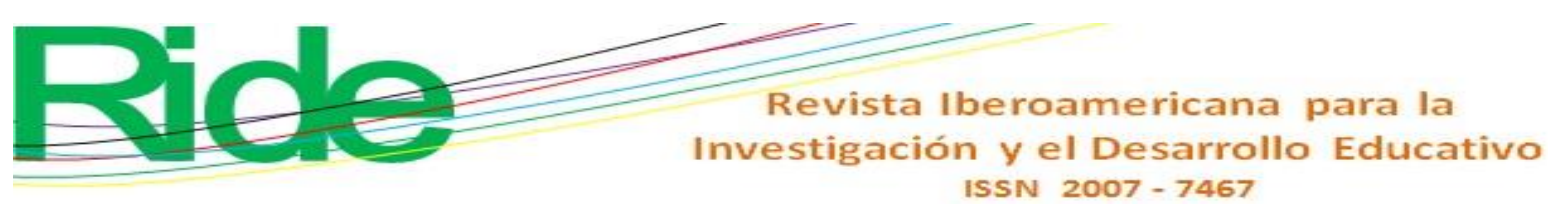

reto de participar en la transferencia de los resultados de sus investigaciones producto de la formación de talento hacia las empresas y la sociedad en general, con la finalidad de que esta apropiación genere riqueza alineada a las políticas públicas para contribuir al desarrollo sostenible del estado de Jalisco.

Palabras clave: agentes heterogéneos, formación de talento, innovación, sector mueblero, vinculación.

\section{Abstract}

The main objective of this article is to explain how the formation of talent and innovation affects the processes of linking that are generated between heterogeneous agents: universities in coordination with civil society and business organizations. The above through a case study on the furniture industry in Jalisco, through the model of Triple, Quadruple and Quintuple Helix. One of the overwhelming results is that the formation of talent and innovation influence the strengthening of the furniture sector of Jalisco, as well as the formation of key actors at the local and national levels for the integration of a network of heterogeneous actors essential for the generation of development and growth of this sector. In this scenario, education institutions face the great challenge of participating in the transfer of the results of their research product of the formation of talent towards companies and society in general, with the purpose that this appropriation generated wealth aligned with public policies to contribute to the sustainable development of the state of Jalisco.

Keywords: heterogeneous agents, talent training, innovation, furniture sector, linkage.

\section{Resumo}

O principal objetivo deste artigo é explicar como o treinamento e a inovação de talentos afetam os processos de vinculação que ocorrem entre as universidades, a sociedade civil e as organizações empresariais. $\mathrm{O}$ exposto acima, através de um estudo de caso sobre a indústria moveleira em Jalisco, através do modelo de hélice tripla, hélice quádrupla e hélice quíntupla. Um dos resultados impressionantes é que o treinamento de talentos e a inovação influenciam o fortalecimento do setor moveleiro de Jalisco. Da mesma forma, no campo da ligação, percebe-se a conformação dos principais atores nos níveis local e nacional para a integração de uma rede de agentes heterogêneos essenciais para a geração de 


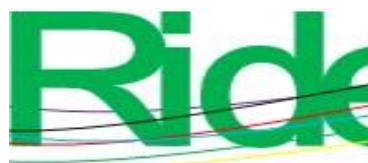

Revista Iberoamericana para la Investigación y el Desarrollo Educativo ISSN $2007-7467$

desenvolvimento e crescimento desse setor. Lá, as instituições de ensino enfrentam o grande desafio de participar da transferência dos resultados de suas pesquisas, como resultado do treinamento de talentos para as empresas e a sociedade em geral, para que essa apropriação gere riqueza alinhada às políticas públicas. contribuir para o desenvolvimento sustentável do estado de Jalisco.

Palavras-chave: agentes heterogêneos, treinamento de talentos, inovação, setor moveleiro, articulação.

Fecha Recepción: Septiembre 2019

Fecha Aceptación: Marzo 2020

\section{Introducción}

El entorno dinámico del quehacer científico se centra en la sociedad basada en el conocimiento, donde, a su vez, la dinámica evolutiva de la economía juega un papel fundamental, al igual que la innovación, la cual toma en cuenta modelos enfocados en la coordinación de actores que intervienen en la generación y aplicación del conocimiento. En este sentido, la formación de talento a través de la relación universidad-empresa-Estado representa un pilar para la transferencia del conocimiento y su aplicación social con miras a generar bienestar y mejorar la calidad de vida de las comunidades y el sector empresarial, es decir, la innovación abierta (Rexhepi, Abazi, Rahdari, Angelova, 2019).

Esta investigación es derivada de una investigación de tesis doctoral y se centra en el carácter multidimensional de la innovación; se focaliza en la relación de vinculación formal e informal de la industria, la universidad, las organizaciones intermedias, la acción de los programas públicos y las estrategias empresariales.

Tiene implicaciones a nivel macro, meso y micro que, en ciertos casos, fortalece al sector y los agentes, y en otros, obstaculiza la acción por la debilidad de vínculos. La cooperación y vinculación entre los agentes heterogéneos que fortalecen y articulan la relación industria-academia-Gobierno (formación, investigación y transferencia de conocimientos) ha sido analizada por múltiples enfoques: desde en el triángulo de Sábato (Sabato y Botano, 1968), que incluye la interrelación del Estado, la industria y la academia hasta la cuádruple y quíntuple hélice .

En casos de éxito, la acción de los niveles (macro, meso y micro) puede generar una integración positiva, articulando la transversalidad de dimensiones tecnológicas, organizativas o de apoyos complementarios que pueden generar soluciones a los problemas 


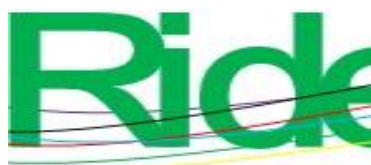

\section{Revista Iberoamericana para la Investigación y el Desarrollo Educativo ISSN $2007-7467$}

de la colaboración interorganizacional. La dimensión micro depende de lo meso y macro, no pueden separarse completamente uno de otro si se quiere entender el contexto y, consiguientemente, solucionar problemas. Estas asumen la colaboración entre lo públicoprivado o el involucramiento de una multiplicidad de actores interdependientes o heterogéneos para generar acciones en conjunto (Casalet y Stezano, 2009). Sin embargo, las soluciones de problemas dependen de las condiciones, del contexto y de las estructuras tanto institucionales como tecnológicas con las que dispone cada actor heterogéneo. De ahí la importancia de analizar la vinculación entre estos agentes heterogéneos que se manifiesta, en este caso, en el sector mueblero de Jalisco.

\section{Metodología}

La metodología que se utilizó fue de enfoque mixto. Por un lado, se describe toda la información obtenida a partir de la encuesta aplicada a empresas integradas a las diferentes asociaciones y cámaras del sector mueblero jalisciense, tales como la Asociación de Fabricantes de Muebles de Jalisco (Afamjal), la Asociación de Fabricantes de Muebles de Ocotlán (Afamo), Cámara Nacional de Comercio (Canaco) de Tlaquepaque y la Cámara de la Industria Mueblera del Estado de Jalisco (Cimejal). La muestra fue de 290 empresas. Por otro lado, se entrevistó a expertos en vinculación de instituciones de educación superior y a expertos en vinculación de diferentes organismos gubernamentales en las dimensiones macro, meso y micro con sus respectivos ejes estratégicos.

Para ello, se procedió a categorizar las variables correspondientes para el análisis, tal y como se muestra en la tabla 1.

Tabla 1. Ejes estratégicos y dimensiones de análisis micro, meso y macro

\begin{tabular}{|l|l|l|l|}
\hline \multicolumn{1}{|c|}{ Ejes Estratégicos } & \multicolumn{3}{c|}{ Dimensiones } \\
\cline { 2 - 4 } & Macro & Meso & Micro \\
\hline Vinculación & Vinculación & Vinculación & Vinculación \\
& macro & meso & micro \\
\hline Apoyos & Apoyos macro & Apoyos meso & Apoyos micro \\
\hline Recursos humanos (RH) & RH macro & RH macro & RH micro \\
\hline
\end{tabular}

Fuente: Elaboración propia 
Explicación de las dimensiones (macro, meso y micro) desde la perspectiva del sector mueblero de Jalisco para la generación de innovación

La perspectiva de participación multinivel que refiere Geels (2006a, 2006b) puede generar una red de gobernanza conformada de actores heterogéneos, la cual, a su vez, constituye la triple, cuádruple y quíntuple hélice para la producción de conocimiento e innovación (Carayannis, Acikdilli, y Ziemnowicz, 2019).

En esta colaboración de múltiples actores en el sector mueblero, la dimensión macro hace alusión al paisaje sociotécnico, a espacios más generalizables, que no están en los nichos ni en el régimen sociotécnico, ya que los cambios vienen desde en el aspecto histórico, a lo largo del tiempo. Estos espacios generalizables se refieren al aspecto de la globalización, los problemas del medio ambiente y cambios culturales que se dan en la industria del mueble influenciados por otros mercados internacionales que, de alguna manera, participan directa o indirectamente en el desarrollo del sector mueblero. Es por eso por lo que, en este nivel, se pueden tomar en cuenta las variables exógenas y endógenas que intervienen en el desarrollo del sector y las condiciones económicas con las que cuenta dicho sector, la cooperación internacional y las políticas públicas de ciencia, tecnología e innovación tanto sectoriales, estatales y nacionales que han guiado a la industria para ser competitiva.

A nivel meso entran los regímenes sociotécnicos (una relación entre lo social y lo técnico), es decir, entran los grupos involucrados de manera directa e indirecta (instituciones gremiales: cámaras y asociaciones); hay una cierta comunicación entre estos grupos, incluso hay una transmisión de conocimiento entre ellos. De esta forma, se toma en cuenta la estructura institucional del sector mueblero tanto gremial, financiera y académica que genera apoyos (económicos, de colaboración, social, etc.) para dicho sector.

A nivel micro se forman los nichos tecnológicos, donde se generan las "innovaciones radicales" a partir de la interacción de los actores, es decir, se puede trabajar en conjunto haciendo investigación y desarrollo (R\&D, por sus siglas en ingles). En este sentido, para el desarrollo de estos nichos en este nivel existen ciertas reglas que juegan con los particulares y no generalizables, las interacciones entre los grupos vinculados a los procesos productivos y de innovación. Por lo tanto, se toman en cuenta las condiciones de las empresas muebleras del estado de Jalisco, el tipo de asociacionismo que tienen con respecto a la vinculación con otros agentes heterogéneos, por ejemplo, si hay vínculos con algunas universidades, centros 


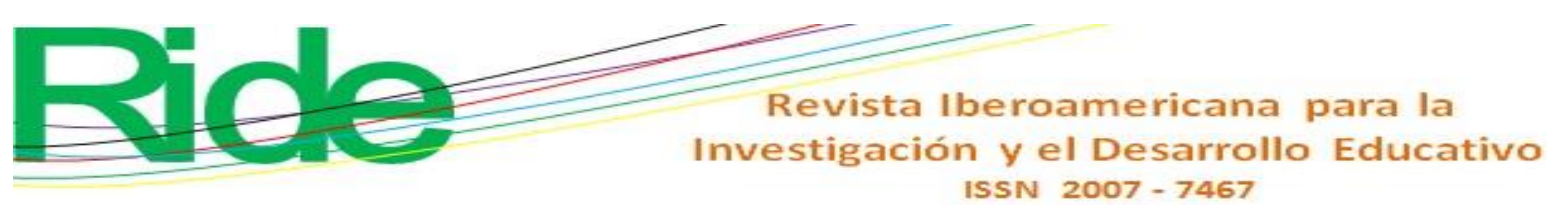

de investigación o alguna otra institución ya sea local, nacional o internacional.

\section{Desarrollo}

\section{El desarrollo de la innovación en diferentes enfoques explicativos}

En este apartado se traza la noción de innovación a partir de los aportes de Bush (julio de 1945), quien se focalizó en la política de investigación científica; de los estudios de Freeman (1975) y Freeman y Soete (1997) sobre "la teoría económica de la innovación industrial", cuyo sustento en gran medida es el análisis de Adam Smith (2011) sobre "la riqueza de las naciones", quien estudió los adelantos de la maquinaria que se usaban en la industria manufacturera e industrial del siglo XVIII, así como de las aportaciones de Marx, que se centró en la "innovación técnica" de los bienes de capital; desde luego a partir de las aportaciones de Schumpeter, (1996), donde la innovación cobra relevancia en la economía sobre todo en el producto, proceso o sistema que se realizaba en las empresas industriales de la primera mitad del XIX. Estas aportaciones de Schumpeter identificaron la red de laboratorios de investigación y de las universidades con la industria que asignaban trabajo profesional con dedicación absoluta; le permitió observar y describir el conocimiento producido en las empresas. También la innovación se nutre de las aportaciones de Nelson y Winter (1982), que se orientaron a evaluar y consolidar la ciencia, tecnología e innovación; Freeman (1975), por su parte, hablaba de un "Sistema Nacional de Innovación”, el cual fue retomado por Lundvall (1992) y Nelson (1993), quienes lo desarrollaron ampliamente y se enfocaron principalmente en las políticas públicas que juegan un papel importante en el desarrollo económico y para la integración de los agentes heterogéneos para la producción de conocimiento e innovación.

Poco después, el adaptamiento del triángulo de Sábato hacia el modelo de hélice; retomado por Etzkowitz y Leydesdorff (1995), lo adoptaron al enfoque de la "triple hélice": universidad-empresa-Gobierno, y más tarde se genera la cuádruple hélice, donde se incluye a la "asociación civil” (Ahonen y Hämäläinen, 2012; Arnkil, Järvensivu, Koski y Piirainen, 2010; Bautista, 2015b; Etzkowitz, 2018). Además, en lo que va del siglo XXI se ha tratado de generar la "quíntuple hélice", que involucra a actores de la sociedad en general; asimismo, la democracia entre las hélices y cuestiones ambientales (Carayannis, Barth y Campbell, 2012; Carayannis y Campbell, 2014; Carayannis, Acikdilli y Ziemnowicz, 2019), y las 


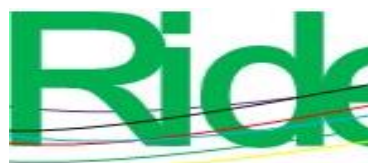

Revista Iberoamericana para la Investigación y el Desarrollo Educativo ISSN $2007-7467$

aportaciones de Geels (2006a, 2006b), las cuales engloban esta quinta hélice para tener una interacción transversal de tipo multinivel (macro, meso y micro).

\section{La vinculación e innovación en el caso del sector mueblero de Jalisco}

El sector mueblero jalisciense ha tenido acercamientos con los mercados internacionales y con algunas instituciones que se dedican exclusivamente a la capacitación de recursos humanos para la especialización; instituciones como el Instituto Tecnológico del Mueble, Madera, Embalaje y Afines (Aidima) de España, por ejemplo, hasta cierto punto han colaborado con el sector para posicionarlo competitivamente. Es evidente que el sector mueblero y maderero ha sido beneficiado por capacitaciones específicas con algunos grupos de países como Alemania, lo cual apunta a elevar la productividad, capacitación en la utilización de tecnología e infraestructura para fortalecer la capacidad instalada en cada una de las empresas, además de las diferentes políticas científicas, tecnológicas y de innovación que ha establecido el Gobierno estatal y nacional para la competitividad del sector mueblero de Jalisco.

En el nivel macro, uno de los aspectos que interviene directa o indirectamente es la cooperación internacional que ha tenido el sector mueblero de Jalisco: las experiencias del sector con otras instituciones académicas internacionales y sobre todo las experiencias en los mercados internacionales y globales.

En la parte meso, por su parte, se muestran todas las instituciones participantes, tomando como referencia las aportaciones que presenta Casalet (2015) para enmarcar este nivel sobre los paradigmas tecnológicos. Estas instituciones han beneficiado hasta cierta forma el desarrollo del sector mueblero.

En el nivel micro, como se aprecia en la figura 1, destaca también el impulso que tiene la industria mueblera hacia el tema de la innovación; se muestran los concursos de diseño del mueble donde se encuentran participando, además de las empresas, estudiantes de diferentes universidades, tales como la Universidad de Guadalajara, el Instituto Tecnológico y de Estudios Superiores de Monterrey, la Universidad Panamericana y la Universidad Autónoma de Guadalajara. Asimismo, participa bajo el modelo de la cuádruple hélice el Gobierno a través del Consejo Estatal de Ciencia y Tecnología de Jalisco (Coecytjal). 
Figura 1. Dimensiones de los ejes estratégicos del sector mueblero de Jalisco
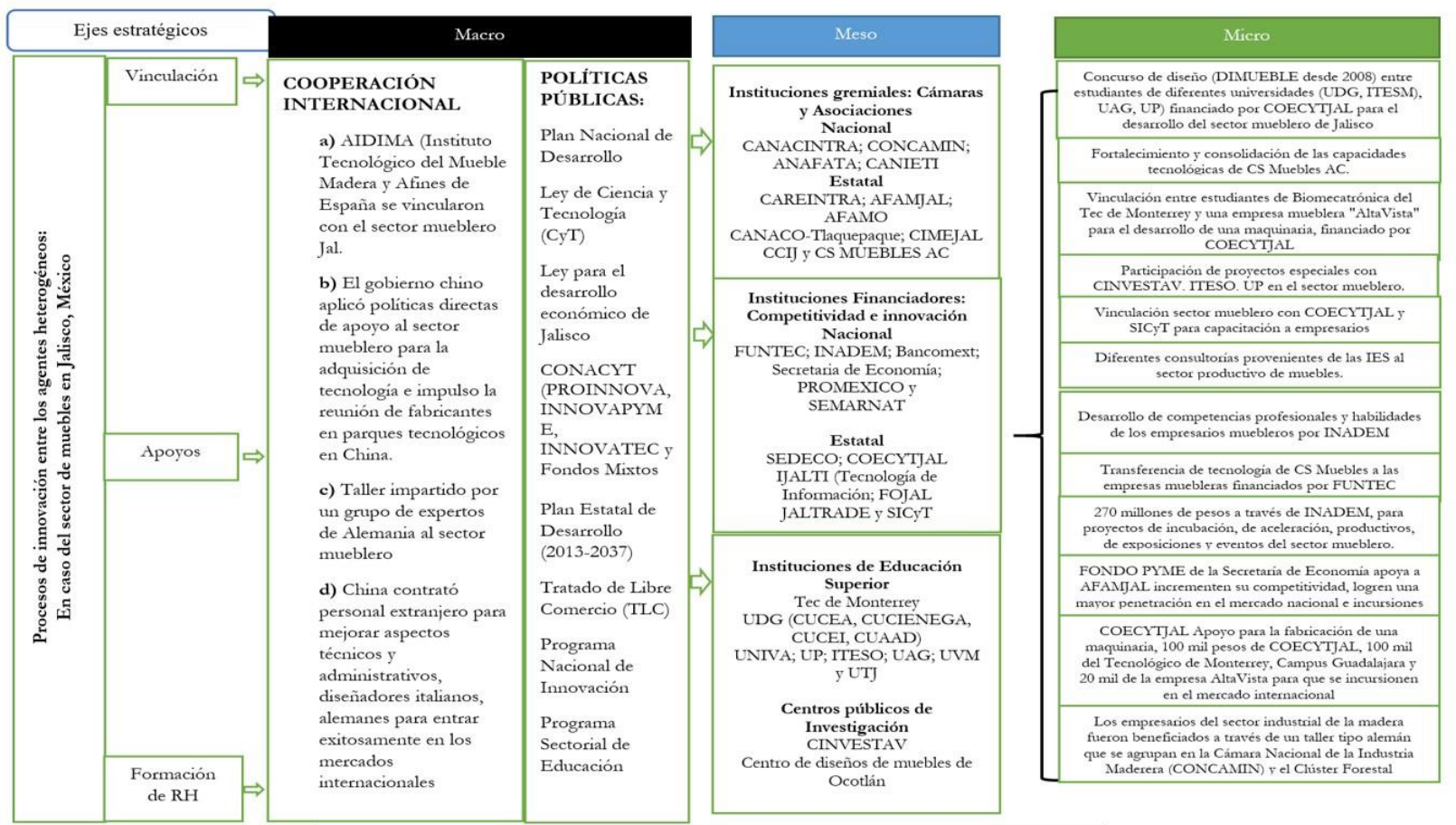

Fuente: Elaboración propia

\section{Cooperación internacional}

La participación del sector mueblero de Jalisco, México, desde los años 90 ha tenido participación en los mercados internacionales. Entre ellos, Estados Unidos ha sido el principal mercado de los empresarios muebleros de Jalisco: sobre todo se han abierto las puertas para exposiciones y eventos, incluso se ha establecido un centro de exposición de muebles en Casa Chicago durante los últimos cinco años. Así pues, se ha venido trabajando a lo largo del tiempo para internacionalizarse, apoyándose con actores económicos (organismos internacionales) y académicos (por ejemplo, Aidima).

De acuerdo con las investigaciones de Lozano (2010), la industria mueblera de Jalisco tuvo una ligera cooperación con la Aidima de los años 90: se apoyó en la instalación de un laboratorio de control de calidad del mueble. Ante esto, el sector mueblero empezó a esforzarse en crear contactos a nivel internacional, se crearon propuestas para asistir en exposiciones internacionales para atraer compradores internacionales y, consecuentemente, fortalecer las exposiciones internacionales en el estado de Jalisco, principalmente en la Zona Metropolitana de Guadalajara (ZMG), Región Ciénega y en el municipio de Tlaquepaque, donde se albergan artesanos muebleros. 


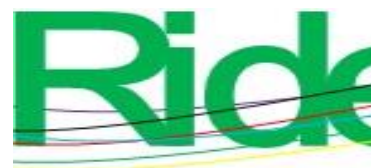

\section{Revista Iberoamericana para la Investigación y el Desarrollo Educativo ISSN 2007 - 7467}

El mercado internacional se caracteriza por la concentración de grandes compradores en multitiendas tipo outlet (IKEA), que se encuentran ubicadas en los países europeos (Francia, Alemania, Reino Unido, Suecia). Por otro lado, existen los vendedores independientes que se ubican por el lado de Italia (Lozano, 2008). Empresas como IKEA son las más innovadores y tienen sucursales en diferentes partes del mundo. De hecho, en 2019 IKEA llegó a México. Además, usan las mejores tecnología para la fabricación de todos sus productos. En este sentido, colaboran con diferentes universidades y otros organismos intermedios para fortalecer las tiendas muebleras y otorgarles un mayor prestigio. Una de las características de estas tiendas es que aprovechan la tecnología que se fabrica en todos los países industriales avanzados y, por lo regular, su inversión es muy alta. Es por eso por lo que sus productos logran un gran impacto, además de que utilizan diferentes estrategias para atraer clientes potenciales de mayor tamaño: un ejemplo claro para que el sector mueblero de Jalisco pueda fortalecer sus capacidades tecnológicas y poder competir en el mercado exterior con los mejores productos, precios, calidad y, sobre todo, en innovación.

En un sondeo realizado en la Expo Muebles del 2012, llevada a cabo en la capital tapatía, académicos de la Universidad de Guadalajara pudieron detectar que varios de los compradores internacionales no habían comprado productos diferentes a los que vieron en años anteriores debido a que no se había ni se ha implementado tecnología de punta en la industria; por lo regular la tecnología que se usa es intermedia (Madrigal, Bautista y Ruiz, 2012).

\section{Políticas públicas nacionales, estatales y sectoriales que marcan la competitividad y la innovación del sector mueblero de Jalisco}

En México existen ciertos programas que dispone el Consejo Nacional de Ciencia y Tecnología (Conacyt), tales como Proinnova, Innovapyme e Innovatec, con el fin de estimular la innovación para el fortalecimiento e impacto en la economía nacional. Asimismo, los fondos sectoriales, fondos mixtos, el Sistema Nacional de Investigadores (SNI), el Programa Nacional de Posgrados de Calidad (PNPC), entre otros, que existen para fortalecer las capacidades y estructuras de innovación tanto de las universidades como de las empresas. 


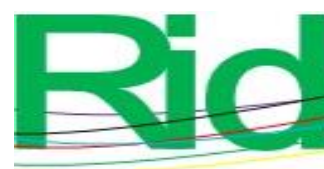

Revista Iberoamericana para la
Investigación y el Desarrollo Educativo
ISSN $2007-7467$

De las empresas que participaron en el estudio, a nivel micro se destaca que $71 \%$ no conoce los apoyos que se otorgan a través de las convocatorias del Conacyt; de los que sí contestaron que conocían dichos apoyos, el mayor de los porcentajes, $15 \%$, apunta al que se proporciona a las pequeñas y medianas empresas (pymes), denominado Innovapymes, seguido del Proinnova con $5 \%$ (ver figura 2).

Figura 2. Apoyos de Conacyt recibidos en las empresas muebleras a nivel micro

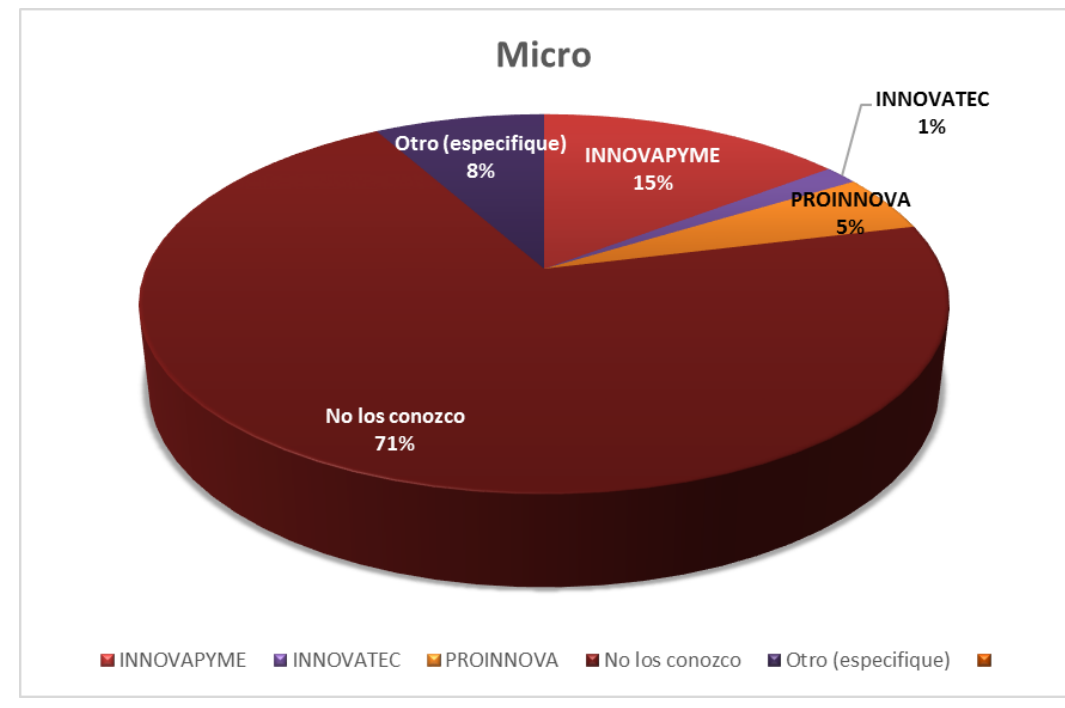

Fuente: Elaboración propia

De forma desglosada, en la pequeña empresa se destaca, análogamente a las cifras anteriores, que $78 \%$ admite no saber de estos apoyos; es de destacar, sin embargo, que $9 \%$ reconoce los programas relacionados al rubro de la innovación, como el Proinnova. Estas empresas, que en su mayoría son familiares, necesitan fortalecer los rubros de vinculación para poder crecer, así como la innovación para poder ser más competitivas a nivel global. Es importante señalar que contar con capital intelectual especializado para responder de forma estratégica en términos de innovación representa todo un reto para estas empresas debido a que no cuentan con el capital económico orientado a la innovación y diseño que se le suele demandar a este tipo de empresas. 


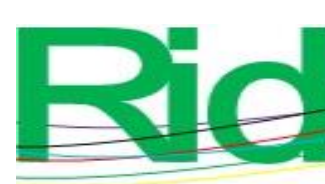

Revista Iberoamericana para la
Investigación y el Desarrollo Educativo
ISSN $2007-7467$

Figura 3. Apoyos de Conacyt recibidos en las empresas muebleras a nivel pequeñas empresas

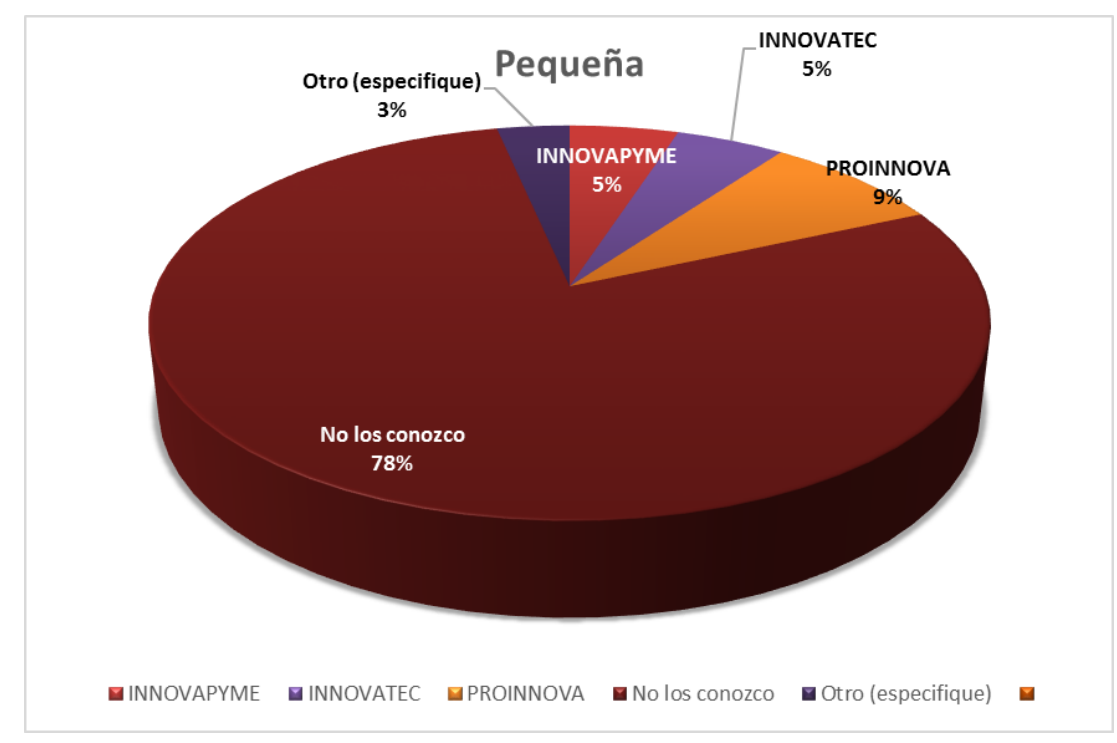

Fuente: Elaboración propia

Para el caso de la mediana empresa, hay un porcentaje mayor de empresas que menciona reconocer algún apoyo de este tipo: tanto Innovapyme como Proinnova destacan con $12 \%$, aunque el mayor porcentaje se concentra en los apoyos que se vinculan en mayor medida a temas de innovación y tecnología, como el Innovatec con $23 \%$. Este tipo de convocatorias se encuentran orientadas a desarrollar proyectos disruptivos para fortalecer competencias creativas, emprendedoras e innovadoras a través de transferencias tecnológicas y de comercialización. Por último, $24 \%$ relaciona otro tipo de apoyos, como los que se ofrecen para fortalecer su competitividad a través de las cámaras. 


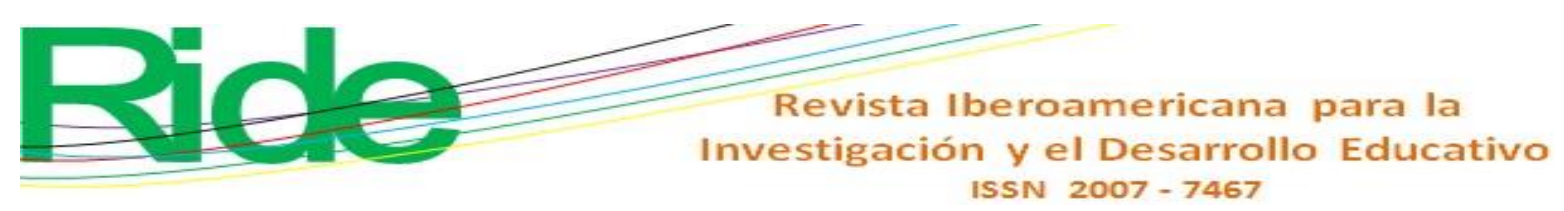

Figura 4. Apoyos de Conacyt recibidos en las empresas muebleras a nivel medianas empresas

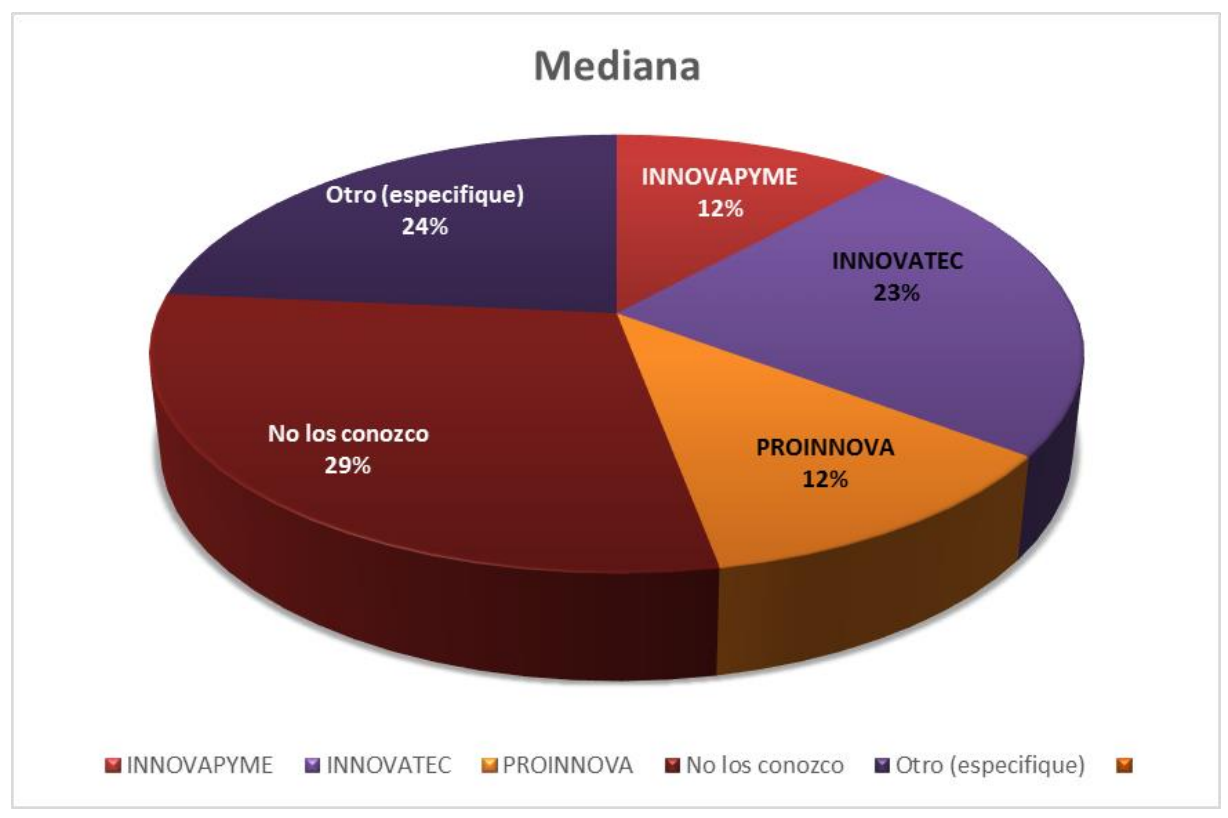

Fuente: Elaboración propia

Las empresas muebleras más consolidadas por el número de empleados y capacidad para su competitividad conocen en su mayoría el programa que se ofrece a través de la convocatoria de Innovatec. Este tipo de convocatoria se caracteriza por estar orientada a los sectores estratégicos de Jalisco. Asimismo, establece una mayor vinculación de las empresas con el sector educativo con la incorporación de estudiantes tanto de licenciatura como de posgrado para que puedan desarrollar proyectos que incorporen elementos de la industria 4.0, como el Internet de las cosas, la inteligencia artificial y la digitalización. 


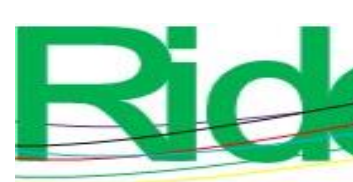

Revista Iberoamericana para la
Investigación y el Desarrollo Educativo
ISSN $2007-7467$

Figura 5. Apoyos de Conacyt recibidos en las empresas muebleras a nivel grandes empresas

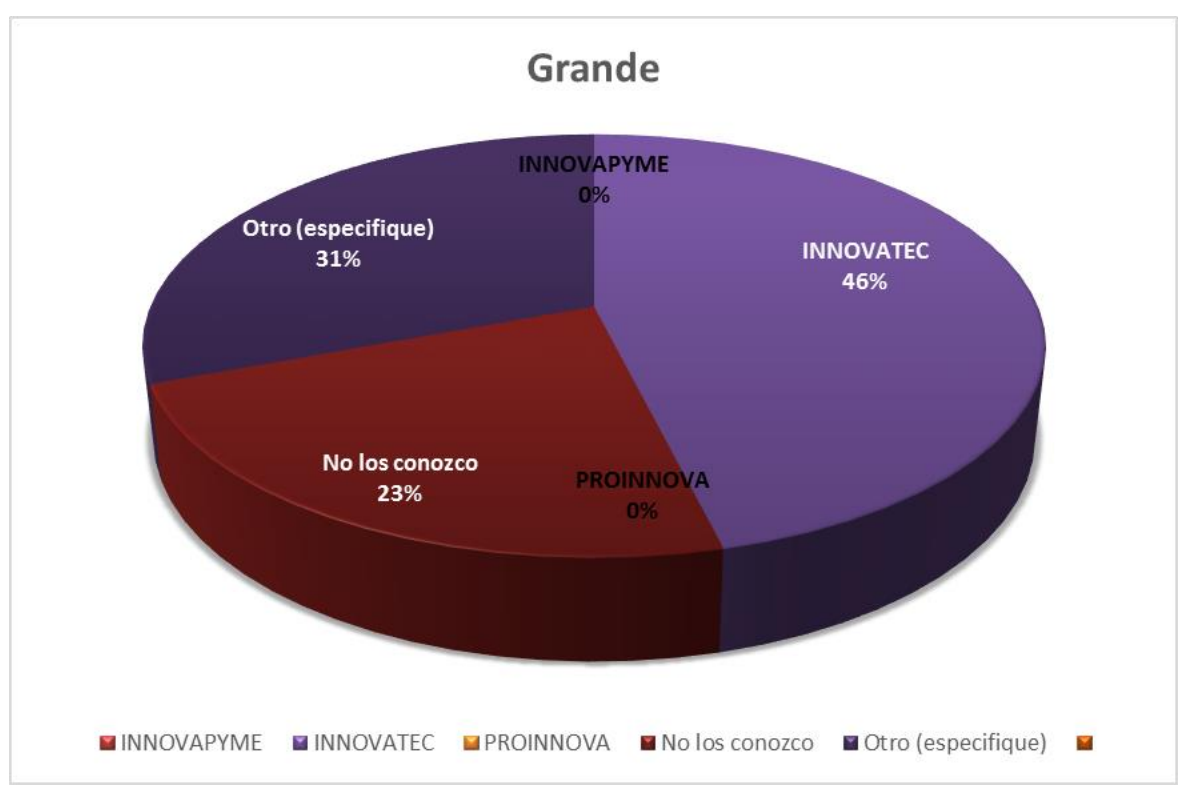

Fuente: Elaboración propia

Para seguir fortaleciendo la innovación en el país, la Ley de Ciencia y Tecnología (CyT), creada en 2002, fue reformulada, primero en 2009 y en una segunda ocasión en 2015, para generar aún más innovación, fortalecer las capacidades de las universidades regionales y nacionales y para apoyar al sector productivo.

Los avances se manifestaron desde el Plan Nacional de Desarrollo (PND) 2013-2018 (Gobierno de la República, 2013); allí se anunciaron algunos objetivos y acciones para que las instituciones de educación superior realizaran vínculos con los sectores productivos y sociales, como una nueva red para la generación de innovación y, consecuentemente, de competitividad. Detalla el objetivo 3.5: "Hacer del desarrollo científico, tecnológico y la innovación pilares para el progreso económico y social sostenible" (Gobierno de la República, 2013, p. 128). Igualmente, durante la administración de Enrique Peña Nieto, se contaba con el Programa Sectorial de Educación 2013-2018 (PSE), que apuntaba hacia la construcción de estructuras innovadoras. También está el Programa Nacional de Innovación (PNI), sustentado en el artículo 3 de la Constitución Política de los Estados Unidos Mexicanos, así como en la Ley de CyT. El PNI comprende la importancia de la innovación en México, la integración de un ecosistema de innovación, donde se incluyen los pilares de innovación que tienen que ver con los mercados nacionales e internacionales, el fortalecimiento empresarial, financiamiento para los proyectos de innovación, el 


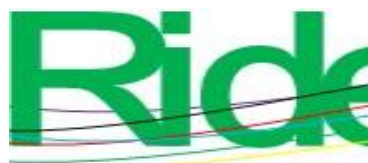

Revista Iberoamericana para la
Investigación y el Desarrollo Educativo
ISSN $2007-7467$

aprovechamiento del capital humano y el marco regulatorio institucional. No hay que olvidar el Programa Especial de Ciencia y Tecnología (Peciti), que proponía fortalecer la apropiación del conocimiento y la innovación basada en las acciones del PND 2013-2018 para detonar el crecimiento científico, tecnológico y de innovación en México (Gobierno de la República, 2013).

A nivel estatal se sitúa el Plan Estatal de Desarrollo de Jalisco (2013-2033), el cual apunta hacia la construcción de agentes heterogéneos (Bautista, 2015a). Este plan ya venía alineado a la perspectiva federal del PND-2013-2018 con el objetivo de impulsar el desarrollo tecnológico, la investigación científica y la innovación por medio de la articulación entre sectores que contribuyan a la formación de capital humano con altos niveles de especialización. Aunado a ello, los objetivos sectoriales: 1) propiciar las condiciones para la vinculación estratégica entre sectores académicos y económicos; 2) promover la innovación y el emprendimiento para el desarrollo científico y tecnológico, y 3) disminuir la brecha digital en los sectores productivo y social de la entidad. El Gobierno jalisciense también ha publicado la denominada Ley de Ciencia, Desarrollo Tecnológico e Innovación del Estado de Jalisco, la cual básicamente hace alusión, en sus primeros artículos, a la realización de actividades científicas, tecnológicas y de innovación impulsada y regulada la estructura gubernamental.

Se cuenta también con un plan sectorial desde la Secretaría de Innovación de Ciencia y Tecnología (SICyT) de Jalisco, que tiene la misión de promover, facilitar e impulsar la creación y la adopción de una cultura innovadora y competitiva, así como la meta de, a partir del 2019, posicionar a Jalisco como el estado más innovador y con el mayor índice de desarrollo tecnológico de México. La SICyT trabaja también con proyectos regionales para el diseño de políticas públicas diferenciadas, recursos humanos de alto nivel acorde a las necesidades locales, ecosistemas científicos tecnológicos para el desarrollo regional e incrementar la inversión en ciencia, tecnología e innovación a nivel estatal y regional, en conjunto con Aguascalientes y Michoacán.

En este sentido, algunos organismos que le apuestan a la innovación en la industria del mueble tapatía son el Coecytjal y la SICyT, desde donde se impulsa, fomenta y coordina el desarrollo de acciones públicas y privadas relacionadas con el avance de la ciencia y la tecnología e innovación, esfuerzos que ya vienen apoyados por el Conacyt a través de los programas de competitividad y de innovación. 


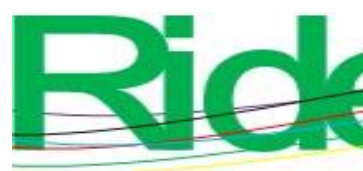

Revista Iberoamericana para la Investigación y el Desarrollo Educativo ISSN 2007 - 7467

En 2015 fue aprobada la Ley de Adquisiciones y Enajenaciones del Estado de Jalisco por el Congreso local. Se trata de la materialización de acuerdos entre los organismos que integran al Consejo de Cámaras Industriales de Jalisco (CCIJ) con los cuales, por ejemplo, se obliga a que las adquisiciones sean locales para que se genere derrama económica en la entidad. En esa línea, los industriales de la madera y mueble pueden verse beneficiados; se espera que en no mucho tiempo se puedan formar clústeres en la entidad, haciendo énfasis en las condiciones de los principales proveedores para que se obtengan mejores costos y eficiencia a través de economías de aglomeración. Como se decía, en la aprobación de esta ley se reunieron los integrantes de los organismos agremiados del sector mueblero, en especial la Cámara Regional de la Industria de Transformación del Estado de Jalisco (Careintra) y la Afamjal, y fue liderada por el presidente del CCIJ, a partir de lo cual los muebleros y otros organismos de la electrónica y la asociación de parques industriales del estado de Jalisco se sumaron a esta nueva ley.

Aunado a todo lo anterior, se pueden mencionar los distintos tratados de libre comercio impulsados por el Gobierno mexicano para la comercialización y exportación e importación de productos de otros países, por ejemplo, el Tratado de Libre Comercio de América del Norte (TLCAN) entre Estados Unidos, Canadá y México que se promulgó desde 1993 y entró en vigor en 1994 para fortalecer las relaciones trilaterales en la realización de negocios. Esto de alguna manera ha beneficiado y afectado en gran medida al sector productivo de muebles a nivel nacional, ya que se ha tratado de impulsar la exportación a estos países; sin embargo, el tipo de arancel es alto y eso implica sin duda un alto costo y gasto para los productores muebleros. Otros de los tratados que se ha firmado es el del Triángulo del Norte, que incluye a países como El Salvador, Guatemala, Honduras y México; el tratado con Costa Rica, con Nicaragua y el Tratado del Grupo de los Tres (G-3) (Colombia, Venezuela y México); tratados con la Unión Europea, con Israel, con Bolivia, Chile, Uruguay, Argentina, entre otros países, con la finalidad de fortalecer las relaciones de negocios con México.

Gracias en parte a estos tratados, el sector industrial de muebles ocupaba el $6 .^{\circ}$ lugar sobre toda la industria manufacturera avanzada en México, ya que en 2010 estaba exportando a nivel mundial un equivalente a $2.23 \%$ del producto interno bruto (PIB) nacional (ProMéxico, 2011). Respecto a la exportaciones mexicanas de muebles, el principal destino es el mercado norteamericano: en los últimos años su porcentaje de participación se mantiene 


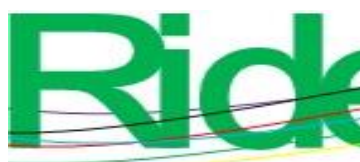

\section{Revista Iberoamericana para la Investigación y el Desarrollo Educativo ISSN $2007-7467$}

entre $3.39 \%$ y $4.29 \%$. En contraste, China ha diversificado sus mercados y su porcentaje de exportaciones a Estados Unidos ha decrecido: para 2011 solo alcanzó $38.65 \%$ del total de sus exportaciones; en tanto los norteamericanos mantienen su preferencia por importar productos chinos: alrededor de $50 \%$ de las importaciones totales de Estados Unidos son chinas.

Para el año 2014, el sector mueblero nacional se había consolidado en el país como el cuarto mayor exportador de muebles, tan solo detrás de China, Canadá y Vietnam. En este sentido, la industria del mueble de Jalisco participa con $16.28 \%$ del PIB sobre la industria manufacturera a nivel nacional: se ocupa el segundo lugar después del Estado de México (Lozano, Madrigal y Bautista, 2012).

La participación del sector mueblero de Jalisco en los mercados internacionales implicó una importación durante el año 2014, según datos que proporcionó la Secretaría de Hacienda y Crédito Público [SHCP] (citada en el Sistema Estatal de Información de Jalisco [Seijal], 2015), de 271702615.28 dólares y una exportación de 373778051.16 dólares; en cambio, en 2017 la importación fue de 181972762.00 dólares y se exportó la cantidad de 447332224.00 dólares (Instituto de Información Estadística y Geográfica [IIEG], 2018).

Figura 6. Exportaciones e importaciones de muebles de Jalisco

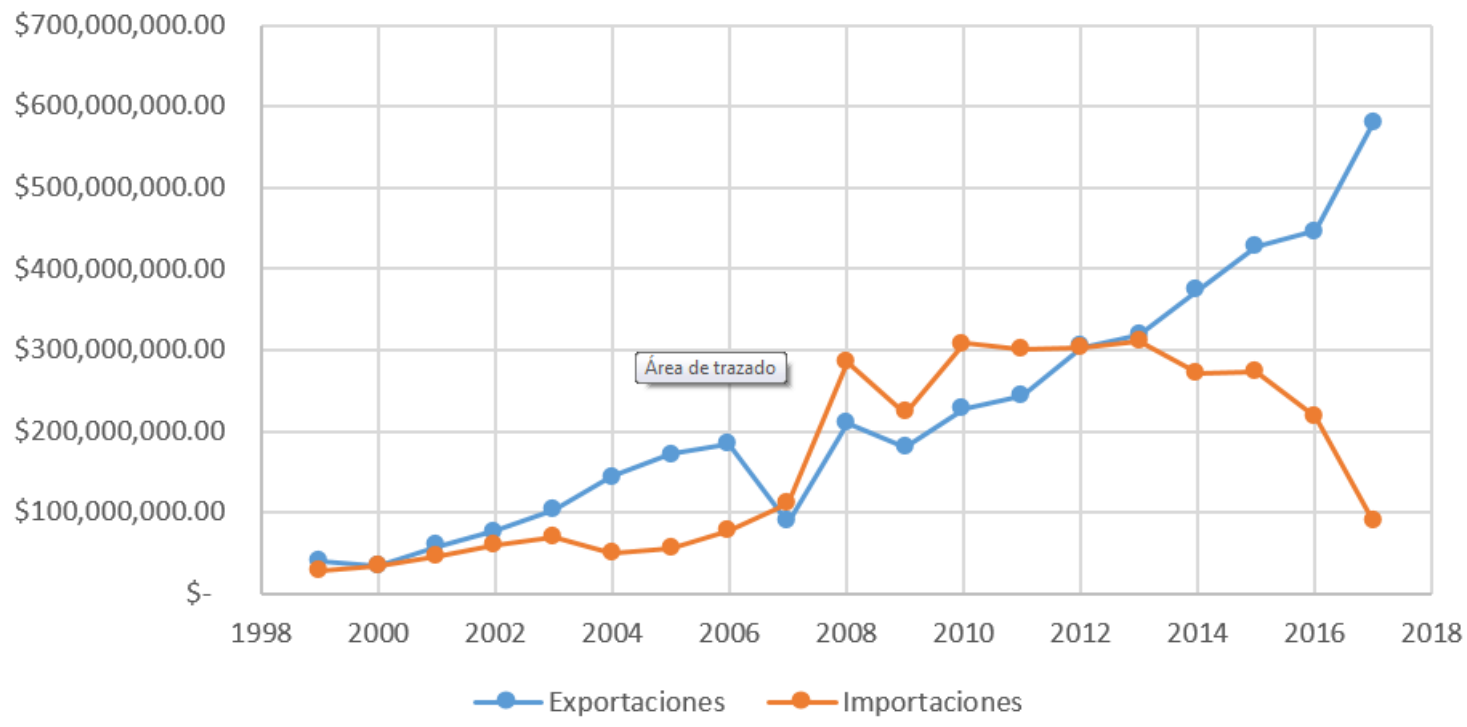

Fuente: Elaboración propia con base en IIEG (2018) 


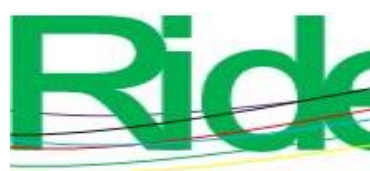

\section{Revista Iberoamericana para la Investigación y el Desarrollo Educativo ISSN 2007 - 7467}

Esto significa que hay una gran diferencia entre lo que se ha exportado contra lo que se ha adquirido, ha habido un incremento esencial sobre la exportación a nivel mundial en los últimos años. Hay una tendencia positiva en lo que corresponde a la exportación de muebles en los mercados internacionales: significa que el sector se está consolidando desde el año 2013 y 2014, a pesar de una baja en los años anteriores, por ejemplo, del 2007 al 2012 predominó la importación de dichos muebles, casi todo un sexenio, pero a partir del 2013, como ya se mencionó, empezó a haber un ligero aumento en la exportación y parece que se ha mantenido. Esto tiene que ver mucho también con las inversiones, políticas públicas y políticas de ciencia, tecnología e innovación tanto del Gobierno nacional como estatal para la exportación. También influyen las tecnologías, diseños y la calidad de productos en el sector mueblero, ya que en los mercados internacionales se exige mucho en estos rubros.

\section{Apoyos generados para el fortalecimiento en la competitividad e innovación del sector mueblero de Jalisco}

La participación de los órganos gubernamentales se constituye a través de acciones y programas específicos hacia el crecimiento de las empresas. Normalmente hay concurrencia de fondos que apoyan al sector productivo y a los que de alguna u otra manera se puede acceder con relativa facilidad, desde luego cubriendo ciertos protocolos, ya sea a través de las cámaras o asociación de muebleros, los cuales reciben ciertos beneficios de esta vinculación entre Gobierno y sector.

En algunas ocasiones fue fomentada la colaboración con organismos gubernamentales con las pequeñas y medianas empresas; en otras ocasiones se generaron proyectos a través de organismos o cámaras empresariales; se apoyó la generación de consorcios tanto de exportación como para mejorar el comportamiento de la cadena productiva; pero lamentablemente en los últimos tres años no habían tenido mucho éxito. Al respecto, en la figura 7 se muestran respuestas contundentes que se basan en las acciones y políticas que se plasman en el Plan Estatal de Desarrollo de Jalisco (2013-2033) y, consecuentemente, de los apoyos recibidos para fortalecer sus capacidades de producción y comercialización.

La vinculación entre los organismos gubernamentales y empresariales es vital para fortalecer la competitividad de las empresas del sector del mueble, sin embargo, no se da de forma significativa. De acuerdo con las empresas que fueron estudiadas, hay acciones 


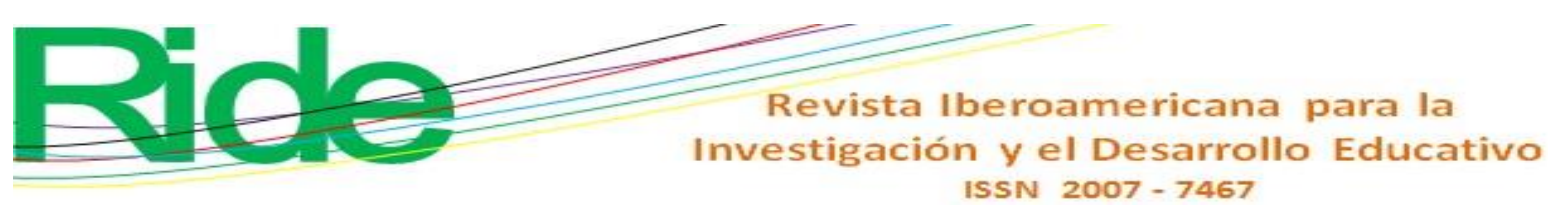

encaminadas a poder atender las políticas de innovación que se enmarcan en el Plan Estatal de Desarrollo ya mencionado, sobre todo tomando en cuenta su apertura, mas no su consolidación. Esto debido a que se ha logrado muy poco avance al no contar con alianzas estratégicas que permitan el impulso para estas empresas.

Figura 7. Participación con organismos gubernamentales y empresariales de las empresas micro

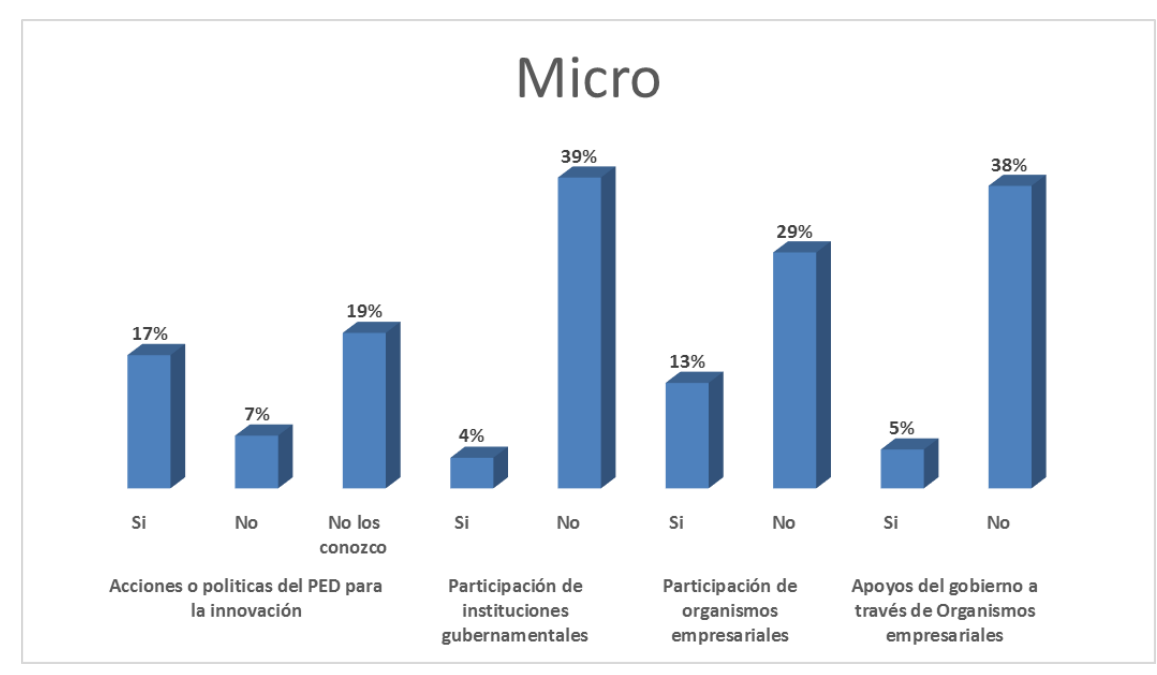

Fuente: Elaboración propia

En cuanto a las empresas pequeñas que se encuentran en la presente investigación, refieren que han participado en acciones y políticas públicas enunciadas en el Plan Estatal de Desarrollo orientadas al campo de la innovación, mayoritariamente al área del diseño; sin embargo, un porcentaje alto, $33 \%$, apunta a la falta de vinculación con instituciones gubernamentales; las empresas refieren mayor vinculación con organismos y cámaras empresariales, algunas de ellas afiliadas a los clúster de la industria mueblera o la Cámara de Comercio de Jalisco. Asimismo, solamente $6 \%$ manifestó tener apoyos del Gobierno a través de otros organismos empresariales. 


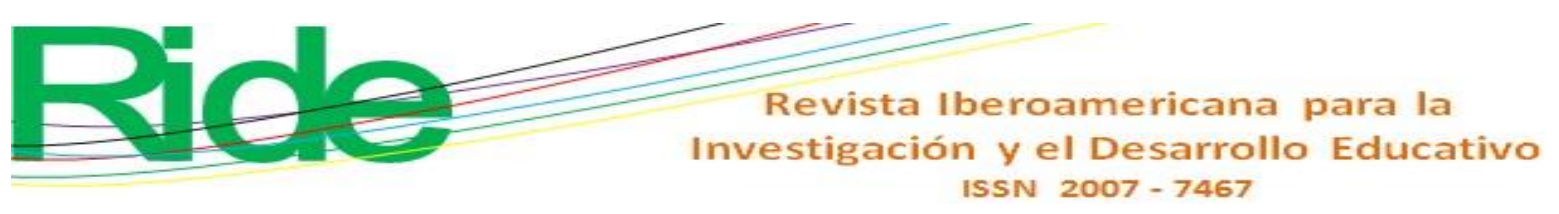

Figura 8. Participación con organismos gubernamentales y empresariales de las empresas pequeñas

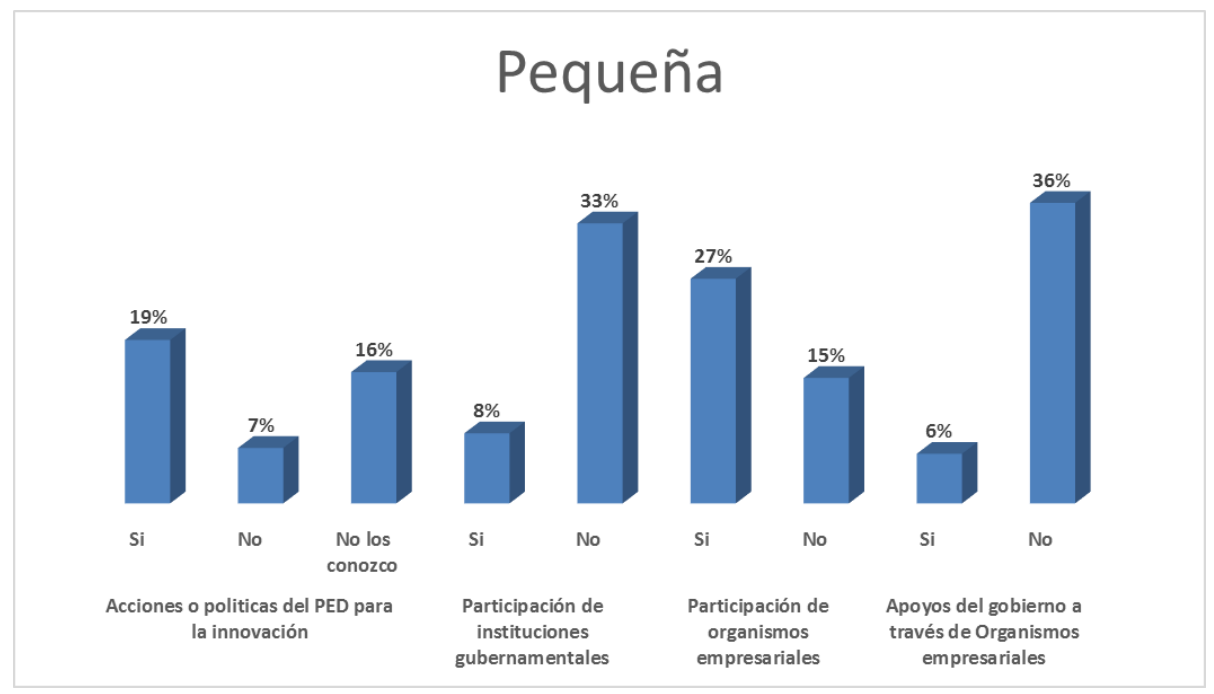

Fuente: Elaboración propia

Para el caso de las empresas medianas que participaron en el estudio, de forma similar a lo arriba mencionado, indican que no existe una relación estrecha de colaboración, tal y como se aprecia en la figura 9; por ejemplo, con la parte de la vinculación gubernamental se obtuvo una respuesta de tan solo $8 \%$; un indicador ligeramente mayor, $9 \%$, con la parte de los organismos pares empresariales, así como las cámaras y los clúster del sector. Aun con todo, $6 \%$ destaca su participación a través de las acciones del Plan Estatal de Desarrollo. 


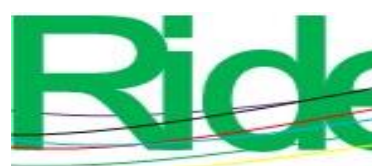

Figura 10. Participación con organismos gubernamentales y empresariales de las empresas medianas

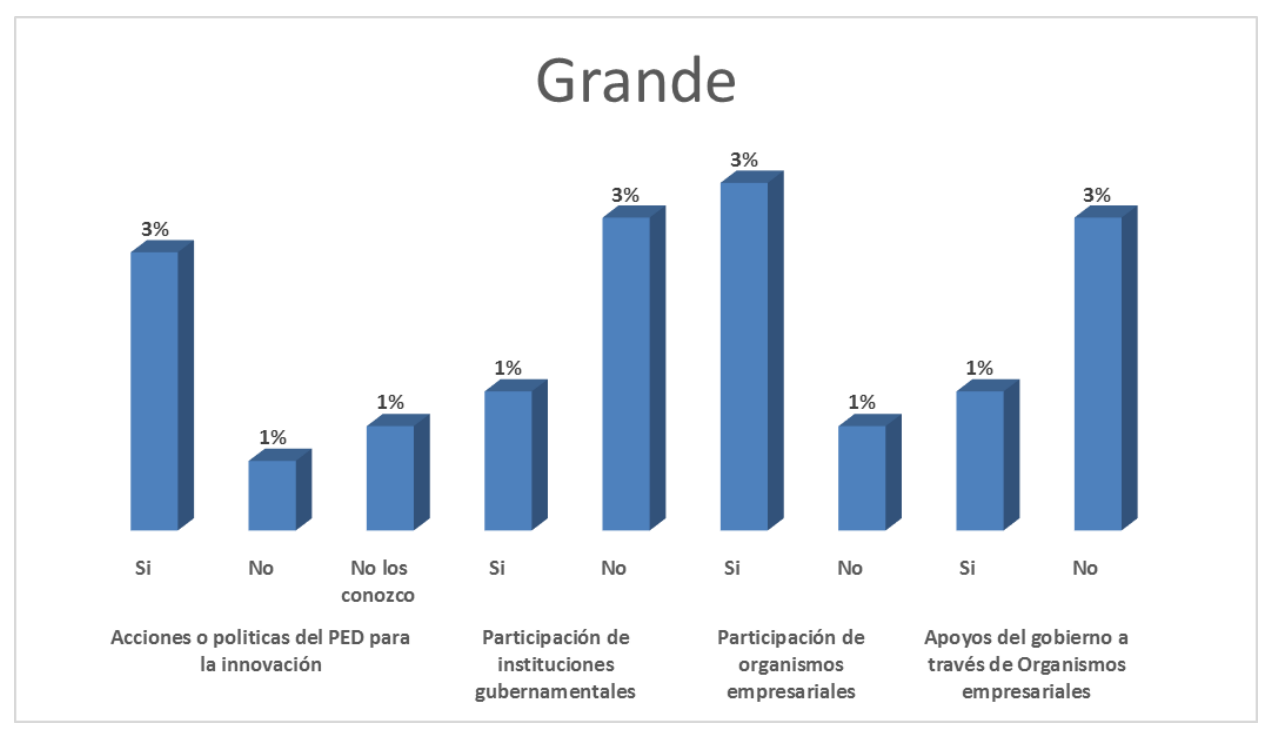

Fuente: Elaboración propia

Con lo anterior descrito, podemos señalar que $38 \%$ de las empresas micros, así como $38 \%$ de las pequeñas, no ha participado nunca con el Gobierno en el periodo del 2006 al 2014, solo $5 \%$ de las micros y $4 \%$ de las pequeñas ha participado durante esos años. Y, por otro lado, $6 \%$ de las empresas medianas y $2 \%$ de las empresas grandes tampoco ha participado con algún ente gubernamental. Solo $5 \%$ de las empresas medianas y $3 \%$ de las grandes participó en algún proyecto con el Gobierno para fortalecer la innovación y la competitividad en sus instalaciones. A pesar de que existen los programas gubernamentales, en algunas universidades no se dan a conocer con un enfoque al desarrollo de las empresas muebleras.

\section{Discusión}

Como se ha puesto de manifiesto, el carácter multidimensional de la innovación establece la relación de vinculación formal e informal por parte de la industria, la universidad, las organizaciones intermedias, la acción de los programas públicos y las estrategias empresariales. En este sentido, las políticas públicas juegan un papel importante en el desarrollo económico y en la integración de los agentes heterogéneos para la producción de conocimiento e innovación, como se establece en la literatura a través de las aportaciones de Nelson y Winter (1982) y Freeman (1975), destaca el papel del "Sistema Nacional de 


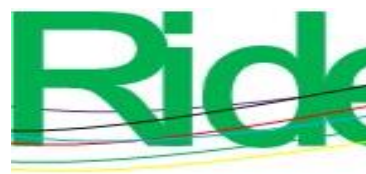

Revista Iberoamericana para la Investigación y el Desarrollo Educativo ISSN $2007-7467$

Innovación", también indicado por Lundvall (1992) y retomado por el mismo Nelson (1993), centrándolo principalmente en las políticas públicas, las cuales adquieren un rol importante en el desarrollo económico y, como se ha mencionado, en la integración de los agentes heterogéneos para la producción de conocimiento e innovación.

De acuerdo con los datos obtenidos en este estudio, las implicaciones de los procesos de innovación se establecen a nivel macro, meso y micro, los cuales, en ciertos casos, fortalecen al sector y a los agentes, y en otros, obstaculizan la acción por la debilidad de vínculos.

Es por ello por lo que la cooperación y vinculación entre los agentes heterogéneos que fortalecen y articulan la relación industria-academia-Gobierno (formación, investigación y transferencia de conocimientos) son necesarios para generar innovación que permita empoderar a las comunidades y generar bienestar y calidad de vida.

Debido a lo anterior, es necesario fortalecer los ecosistemas de innovación, donde se vinculen de forma proactiva y recíproca los mercados nacionales e internacionales, retomando la competitividad empresarial, así como diversificando las fuentes de financiamiento para los proyectos de innovación, el aprovechamiento del capital humano y el marco regulatorio institucional.

\section{Conclusiones}

Desde hace más de cuatro décadas, el sector mueblero ha tenido participación en mercados internacionales con sus exportaciones e interacciones con empresas y organismos de talla mundial, aún no se explican, sin embargo, las estrategias que han utilizado para llegar a estas alturas: la producción de esta ocupa los primeros lugares a nivel nacional. Lo que se ha concluido en este trabajo derivado de una tesis doctoral es que se detectó la conformación de varios actores clave, agrupaciones de organismos empresariales locales, estatales e incluso nacionales, así como la participación del Gobierno (federal, estatal y municipal), aunque con poca participación de otros agentes heterogéneos del lado del sector académico (como las instituciones de educación superior, centros públicos de investigación, agentes intermedios, etc.) en el sector mueblero. Si bien desde el PND 2013-2018 (Gobierno de la República) se refirió la detonación la innovación en México, no se ha logrado formar un capital humano contundente en el sector con altos niveles de especialización. 


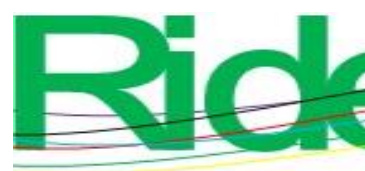

Revista Iberoamericana para la Investigación y el Desarrollo Educativo ISSN 2007 - 7467

Se concluye que se requiere la formación de talento humano especializado en el sector mueblero, a partir del involucramiento de las universidades; hace falta impulsar esa vinculación con la demanda del sector productivo. Aunque han existido apoyos por parte del Gobierno estatal para fortalecer la competitividad e innovación en el sector, no se ha logrado del todo esta formación de talento, una muestra de ello es que $82 \%$ de las empresas micros, pequeñas y medianas desconocen los apoyos y nunca han participado en este fortalecimiento. Esto significa que los apoyos son pocos en cuanto a la formación de talento para la innovación.

La participación del sector académico en específico con el sector mueblero refleja entre baja y mediana complejidad en los procesos de vinculación con diferentes actores heterogéneos en el estado de Jalisco. Esto significa que existe poca participación de las universidades (públicas y privadas), centros públicos de investigación, entre otros, y por tanto, baja participación de estudiantes de diseño en el sector mueblero, consultorías universitarias, al igual que apoyos que fueron creados especialmente para el impulso y la promoción del sector mueblero de Jalisco por parte del Gobierno estatal y federal.

Uno de los concursos que realiza la Afamjal, titulado Dimueble, vinculación con estudiantes del Tecnológico de Monterrey para la realización de un maquinaria, fondos obtenidos a través del Inadem y el Fondo de Apoyo para la Micro, Pequeña y Mediana Empresa, los programas de innovación de Conacyt, pese a ser desconocidas por la mayoría de la muestra aquí participante, estas acciones de los agentes heterogéneos juegan un papel importante para el desarrollo económico del sector, ya que pueden provenir de la investigación, la gestión del conocimiento, las políticas de ciencia, tecnología e innovación y del Gobierno en la orientación de las políticas públicas y de la acción de las empresas y la cadena de valor donde se integran.

En el cuadro de las dimensiones macro, meso y micro se ejemplifican las acciones llevadas a cabo entre empresas con el sector académico, que sirven como base para la creación de políticas públicas y para detonar proyectos conjuntos. Esta dimensión micro alude a más allá de una simple cooperación o firma de convenios, es decir, representa y muestra resultados llevadas a cabo interinstitucional y con otros agentes heterogéneos.

Para finalizar, vale la pena recalcar que hay un desaprovechamiento de los fondos de innovación que están disponible por parte del Gobierno; el reflejo de los resultados es poco favorable para el sector mueblero en ese sentido. 


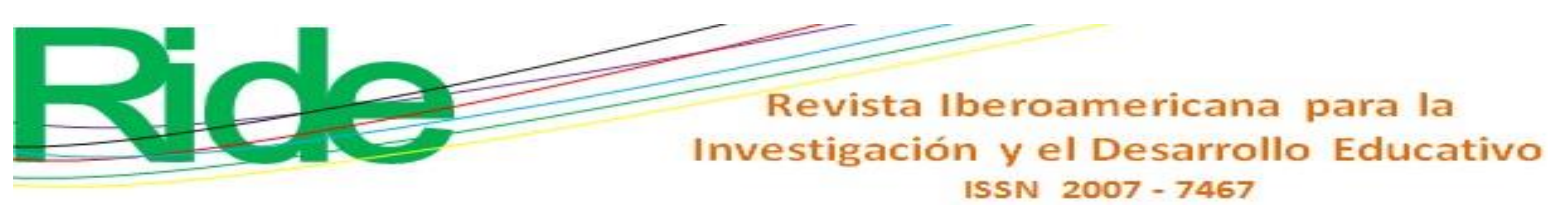

Futuras investigaciones

La siguiente investigación que sigue es validar la formación de talento para la innovación a nivel nacional, con base en modelos innovadores y, consecuentemente, determinar la transferencia de conocimiento científico, tecnológico y de innovación en sectores productivos, como el del mueble y el sector tecnológico con las universidades a nivel estatal y nacional.

\section{Referencias}

Ahonen, L. and Hämäläinen, T. (2012). CLIQ: A Practical Approach to the Quadruple Helix. In MacGregor, S. and Carleton, T. (eds.), Sustaining Innovation. Collaboration Models for a Complex World (pp. 15-29). London, England: Springer.

Arnkil, R., Järvensivu, A., Koski, P. and Piirainen, T. (2010). Exploring Quadruple Helix: Outlining User-Oriented Innovation Models. Tampere, Finland: University of Tampere.

Bautista, E. (2015a). La importancia de la vinculación universidad-empresa-gobierno en México. Revista Iberoamericana para la Investigación y el Desarrollo Educativo. 5(9). Recuperado de https://www.ride.org.mx/index.php/RIDE/article/view/106/464.

Bautista, E. (2015b). La vinculación entre agentes heterogéneos para la producción de conocimiento e innovación. Revista Iberoamericana para la Investigación y el Desarrollo Educativo, 5(10), Recuperado de https://www.ride.org.mx/index.php/RIDE/article/view/112/496

Bush, V. (July 1945). As We May Think. The Atlantic. Retrieved from https://www.theatlantic.com/magazine/archive/1945/07/as-we-may-think/303881/.

Carayannis, E. G. and Campbell, D. (2014) Developed democracies versus emerging autocracies: arts, democracy, and innovation in Quadruple Helix innovation systems. Journal of Innovation and Entrepreneurship Springer, 3(12). Retrieved from doi.org/10.1186/s13731-014-0012-2.

Carayannis, E. G., Acikdilli, G. and Ziemnowicz, C. (2019). Creative Destruction in International Trade: Insights from the Quadruple and Quintuple Innovation Helix Models. Journal of the Knowledge Economy. Retrieved from doi.org/10.1007/s13132-019-00599-z. 


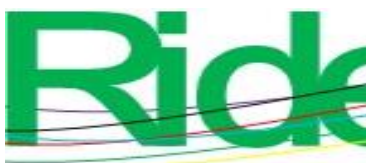

Revista Iberoamericana para la Investigación y el Desarrollo Educativo ISSN $2007-7467$

Carayannis, E. G., Barth, T. D. and Campbell, D. (2012). The Quintuple Helix innovation model: global warming as a challenge and driver for innovation. Journal of Innovation and Entrepreneurship, 1(2). Retrieved from doi.org/10.1186/2192-5372$1-2$

Casalet, M. (2015). El mito de Sísifo: Avances y nuevos desafíos en la apropiación de los paradigmas tecnológicos. En Santos, M. J. y Cruz, R. D. (coords.), Innovación tecnológica y procesos culturales. Perspectivas teóricas (pp. 215-230). Ciudad de México, México: Fondo de Cultura Económica.

Casalet, M., y Stezano, F. (2009). Cambios institucionales para la innovación: nuevos instrumentos de política científica y tecnológica. El caso del consorcio XignuxConacyt. En Villavicencio, D. y López de Alba, P. L. (coords.), Sistemas de innovación en México: Regiones, redes y sectores (pp. 187-215). México: Plaza y Valdés.

Etzkowitz, H. (2018). Innovation Governance: From the "Endless Frontier" to the Triple Helix. In Meusburger P., Heffernan M. and Suarsana L. (eds.), Geographies of the University. Cham, Switzerland: Springer.

Etzkowitz, H. and Leydesdorff, L. (1995). The Triple Helix - University-IndustryGovernment Relations: A Laboratory for Knowledge-Based Economic Development. EASST Review, 14(1), 14-19.

Freeman, C. (1975). La teoría económica de la innovación industrial. Madrid, España: Alianza Editorial.

Freeman, C. and Soete, L. (1997). The Economics of Industrial Innovation. London, England: Routledge.

Geels, F. W. (2006a). Co-evolutionary and multi-level dynamics in transitions: The transformation of aviation systems and the shift from propeller to turbojet (19301970). Technovation, 26(9), 999-1016. Retrieved from doi.org/10.1016/j.technovation.2005.08.010.

Geels, F. W. (2006b). Multi-level perspective on system innovation: relevance for industrial transformation. In Olsthoorn, X. and Wieczorek, A., Understanding Industrial Transformation: Views from Different Disciplines (pp. 163-186). Dordrecht, Netherlands: Springer. 


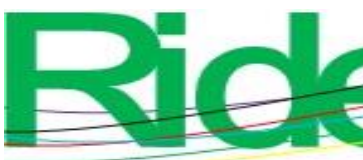

Revista Iberoamericana para la Investigación y el Desarrollo Educativo ISSN 2007 - 7467

Gobierno de la República. (2013). Plan Nacional de Desarrollo 2013-2018. México: Gobierno de la República .

Instituto de Información Estadística y Geográfica [IIEG]. (2018). Industria mueblera. Ficha sectorial. Jalisco, México: Instituto de Información Estadística y Geográfica. Recuperado de https://www.iieg.gob.mx/contenido/Economia/fs_Mueblera.pdf.

Lozano, K. (2008). La relación local-global y la perspectiva de los sistemas productivos de muebles. En Rodriguez, R. A. (coord.), Teoría, metodología y estudios de caso de desarrollo local (pp. 135-168). Guadalajara, México: Universidad de Guadalajara.

Lozano, K. (2010). Desarrollo local a partir de los sistemas productivos locales: el caso de la industria mueblera de Jalisco. (tesis doctoral). Universidad Nacional Autónoma de México, Ciudad de México. Recuperado de http://www.economia.unam.mx/cedrus/publicaciones/tesis/tesis-doctorado.html.

Lozano, K., Madrigal, T. y Bautista, E. G. (2012). Estratégicas empresariales del sector muebles de Jalisco, ante la competencia China y el rol del clúster. (avance de investigación). Recuperado de https://www.academia.edu/35276919/ESTRATEGIAS_EMPRESARIALES_DEL_ SECTOR_MUEBLES_DE_JALISCO_ANTE_LA_COMPETENCIA_CHINA_Y_ EL_ROL_DEL_CLUSTER.

Lundvall, B. A. (1992). National Systems of Innovation: Towards a Theory of Innovation and Interactive Learning. London, England: Pinter.

Madrigal, E., Bautista, E. y Ruíz, R. (2012). El mueble mexicano y su competitividad versus el asiático: percepción comprador internacional. Red Internacional de Investigadores en Competitividad, 6(1). Recuperado de https://www.riico.net/index.php/riico/article/view/438.

Nelson, R. R. (1993). National Innovation Systems: A Comparative Study. Oxford, England: Oxford University Press.

Nelson, R. R. and Winter, S. G. (1982). An Evolutionary Theory of Economic Change. Massachusetts, England: Harvard University Press.

ProMéxico. (2011). Diseñado en México. Mapa de ruta de diseño, ingeniería y manufactura avanzada. Ciudad de México, México: ProMéxico. Recuperado de https://www.gob.mx/cms/uploads/attachment/file/60156/MRT-ManufacturaAvanzada.pdf. 


\begin{tabular}{|c|c|}
\hline Rol de Contribución & Autor (es) \\
\hline Conceptualización & $\begin{array}{l}\text { Principal Evelio Gerónimo Bautista, igual Rocío Calderón } \\
\text { García }\end{array}$ \\
\hline Metodología & $\begin{array}{l}\text { Principal Evelio Gerónimo Bautista, igual Rocío Calderón } \\
\text { García }\end{array}$ \\
\hline Software & Evelio Gerónimo Bautista \\
\hline Validación & $\begin{array}{l}\text { Principal Evelio Gerónimo Bautista, igual Rocío Calderón } \\
\text { García }\end{array}$ \\
\hline Análisis Formal & $\begin{array}{l}\text { Principal Evelio Gerónimo Bautista, igual Rocío Calderón } \\
\text { García }\end{array}$ \\
\hline Investigación & $\begin{array}{l}\text { Principal Evelio Gerónimo Bautista, igual Rocío Calderón } \\
\text { García }\end{array}$ \\
\hline Recursos & Principal Evelio Gerónimo Bautista, \\
\hline Curación de datos & $\begin{array}{l}\text { Principal Evelio Gerónimo Bautista, igual Rocío Calderón } \\
\text { García }\end{array}$ \\
\hline $\begin{array}{l}\text { Escritura - Preparación del } \\
\text { borrador original }\end{array}$ & $\begin{array}{l}\text { Principal Evelio Gerónimo Bautista, igual Rocío Calderón } \\
\text { García }\end{array}$ \\
\hline $\begin{array}{l}\text { Escritura - Revisión y } \\
\text { edición }\end{array}$ & $\begin{array}{l}\text { Principal Evelio Gerónimo Bautista, igual Rocío Calderón } \\
\text { García }\end{array}$ \\
\hline Visualización & $\begin{array}{l}\text { Principal Evelio Gerónimo Bautista, igual Rocío Calderón } \\
\text { García }\end{array}$ \\
\hline Supervisión & $\begin{array}{l}\text { Principal Evelio Gerónimo Bautista, igual Rocío Calderón } \\
\text { García }\end{array}$ \\
\hline $\begin{array}{l}\text { Administración de } \\
\text { Proyectos }\end{array}$ & $\begin{array}{l}\text { Principal Evelio Gerónimo Bautista, igual Rocío Calderón } \\
\text { García }\end{array}$ \\
\hline Adquisición de fondos & $\begin{array}{l}\text { Principal Evelio Gerónimo Bautista, igual Rocío Calderón } \\
\text { García }\end{array}$ \\
\hline
\end{tabular}

